\title{
An intranuclear microsporidian in lumpfish Cyclopterus lumpus
}

\author{
J. E. Mullins, M. Powell, D. J. Speare, R. Cawthorn \\ Department of Pathology and Microbiology, Atlantic Veterinary College, University of Prince Edward Island, \\ Charlottetown, Prince Edward Island, Canada C1A 4P3
}

\begin{abstract}
Chronic mortalities in lumpfish Cyclopterus lumpus raised in a saltwater recirculation system were associated with the presence of an intranuclear microsporidian. Morphologic changes were characterized by infiltration of lymphocyte-like cells predominantly in the renal interstitium and also in the spleen, liver, gills, stomach, pyloric caecae, heart, ovary and mesenteric fat. Affected cell nuclei contained 1 to more than 6 spherical to oval eosinophilic bodies which stained poorly with hematoxylin and eosin and Giemsa. Ultrastructurally, spores were ovoid $(2.1 \times 1.0 \mu \mathrm{m})$ with a polar tube with 11 turns. The morphology of these spores place them in the genus Enterocytozoon. These spores resemble E. salmonis in salmonids, and Microsporidia rhabdophilia in the rodlet cells of salmonids.
\end{abstract}

KEY WORDS: Microsporidian - Enterocytozoon - Lumpfish

\section{INTRODUCTION}

Microsporidia are common intracellular protozoan parasites observed in many species of animals. Although numerous species occur in fish, there are few reports of microsporidia found within the host cell nucleus. Modin (1981) described Microsporidium rhabdophilia in the nuclei of rodlet cells of several species of salmonids in fresh water. However, the presence of these parasites was not associated with clinical signs or disease.

Mortalities and disease associated with Enterocytozoon salmonis within the host cell nucleus were described in chinook salmon Oncorhynchus tshawytscha in fresh water (Hedrick et al. 1990, Morrison et al. 1990) and in salt water (Elston et al. 1987). These infections were characterized by severe anaemia (Elston et al. 1987) and lymphoblastosis (Hedrick et al. 1990, Morrison et al. 1990). The cell type involved was initially believed to be a haematopoietic precursor (Elston et al. 1987) but was later determined to be a lymphocyte precursor (Hedrick et al. 1990).

This report describes the clinical, histopathological and ultrastructural features of an intranuclear micro- sporidian associated with chronic mortalities in saltwater cultured lumpfish Cyclopterus lumpus.

\section{MATERIALS AND METHODS}

Samples of moribund fish from a saltwater recirculation facility were submitted to the Fish Health Unit, Atlantic Veterinary College, Charlottetown, PEI, Canada, for histopathological examination on 4 occasions (27 November 1992; 14 January, 11 February and 8 March 1993). A total of 17 fish were examined. Of these, 15 were 0 to $12 \mathrm{mo}, 1$ was older than $1 \mathrm{yr}$ and 1 was older than $2 \mathrm{yr}$.

Portions of liver, kidney, gill, heart, spleen, intestine, pyloric caecae, gonads and brain were fixed in Bouin's solution for 12 to $24 \mathrm{~h}$. Tissue samples were dehydrated in ethanol, embedded in paraffin wax and sectioned at $5 \mu \mathrm{m}$ thickness. Sections were stained with hematoxylin and eosin, Giemsa, toluidine blue and periodic acid Schiff (PAS) (Luna 1968).

Internal organs from a separate submission of frozen fish were processed following the plankton centrifuge method (O'Grodnick 1975) and examined with a Zeiss 
microscope after staining with Giemsa and Gram stains. The mixture was then pelleted by centrifugation and fixed in $2.5 \%$ glutaraldehyde in $0.1 \mathrm{M}$ sodium cacodylate buffer at $4{ }^{\circ} \mathrm{C}$ overnight, then postfixed in $1 \%$ osmium tetroxide for $1 \mathrm{~h}$ at room temperature. The tissue pellet was minced and both pelleted spores and lumpfish tissue were dehydrated in an ascending gradient of ethanols (50 to $100 \%$ ), transferred to propylene oxide and then embedded in an epon/araldite resin. Sections were cut and examined as described below. Kidney tissue from moribund fish was collected for ultrastructural examination following histological confirmation of microsporidiosis. It was fixed in $2 \%$ glutaraldehyde in a $0.1 \mathrm{M}$ sodium cacodylate buffer overnight at $4^{\circ} \mathrm{C}$. The tissue was then postfixed in $1 \%$ osmium tetroxide in the same buffer for $1 \mathrm{~h}$ at room temperature; dehydrated in a graded series of ethanols and embedded in epon/araldite resin. Semithin sections $(0.55 \mu \mathrm{m})$ were cut and stained with toluidine blue for light microscopy and ultrathin sections (70 nm) stained with uranyl acetate and lead citrate. Ultrathin sections were examined with a Hitachi $\mathrm{H} 600$ electron microscope.

\section{RESULTS}

\section{Gross signs}

Bilateral exophthalmos and moderate to marked branchial pallour were the prominent external signs. Internally there was marked renomegaly, hepatic and cardiac pallour and in some fish small amounts of clear to serosanguinous peritoneal fluid.

\section{Plankton centrifuge method}

High numbers of spores were successfully extracted. They stained positive with Giemsa and Gram stains and were structurally identical to those in intact tissue as described below.

\section{Histopathology}

Microscopic changes were characterized by severe infiltration of lymphocyte-like cells in renal (Fig 1) and splenic interstitia. These cells were also noted in hepatic sinusoids (Fig. 2), branchial central venous sinuses, the lamina propria and submucosa of the stomach and pyloric caecae (Fig 3), mesenteric fat, sinuses of the heart, pancreas and in the ovary of 1 fish (Fig. 4). Infected cells were spherical with a large nucleus and thin rim of basophilic cytoplasm. The nucleus contained 1 to more than 6 eosinophilic, spherical to oval bodies. These eosinophilic structures stained poorly with Giemsa, and were PAS and toluidine blue negative in wax-embedded tissue but toluidine blue positive in resin embedded semithin tissue. All fish examined were infected.

\section{Ultrastructural pathology}

Microsporidian spores were seen located within the nuclei of principally spheroid cells which resembled lymphoblasts and, occasionally, within the nucleus of lymphocytes within the blood vessels of the kidney (Fig. 5). Parasitized cells had a large prominent central nucleus with even dispersion of chromatin, and contained few organelles, mitochondria and occasional, profiles of rough endoplasmic reticulum (Fig. 6). Interspersed among cells containing mature microsporidian spores were pleomorphic cells typified by an electron-lucent cytoplasm containing numerous lysosomes and multivesicular bodies. Often the plasma and nuclear membranes of these cells would be disrupted and the microsporidian spores were located within the cytoplasm rather than the nucleus (Fig. 7). In addition to lymphoblast-like cells containing mature spores, there were numerous irregularly polygonal cells with a large centrally located nucleus. Within the nucleus of these cells were many rod-like and circular structures within a membrane (Figs. 8 \& 9). Several circular structures were arranged linearly (Fig. 9). This intranuclear membrane-bounded structure was distinct from cell nucleoli. Other organelles in these lymphoblast-like precursor cells were rare; occasional mitochondria and profiles of smooth endoplasmic reticulum and golgi with 4 or 5 flattened cisternae were observed but lysosomes were rare and multivesicular bodies were never seen. Occasionally the pre-spore stages of the parasite were seen in the nucleus of circulating lymphocytes (Fig. 5)

\section{Spore morphology}

The microsporidian spores were oval in shape and infiltrated poorly with epon/araldite resin. Typically their dimensions were $2.1 \mu \mathrm{m}$ long by $1.0 \mu \mathrm{m}$ wide. Spores had few discernable internal structures. Primarily they contained a polar tube with typically 11 coils, a polaroplast and a posterior vacuole (Fig. 10). Within this vacuole were linear lamellar structures (Fig. 11). The polar tube comprised 2 components, an outer sheath and an inner core (Fig. 12). Occasionally this core was more electron-dense than the outer sheath (Fig. 12). The microsporidian spore was surrounded by an irregular electron-lucent coat, the chitinous endospore, external to the plasma membrane (Fig. 12). 


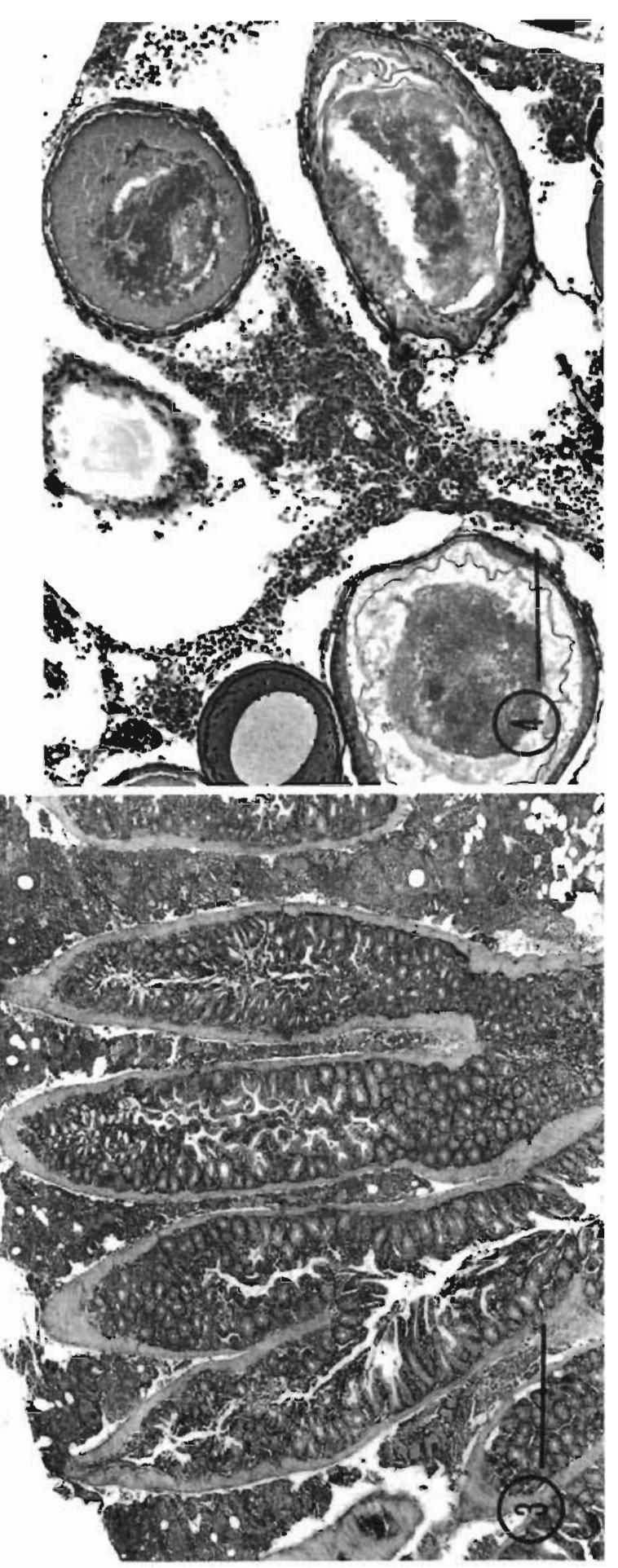

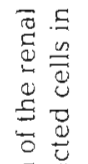

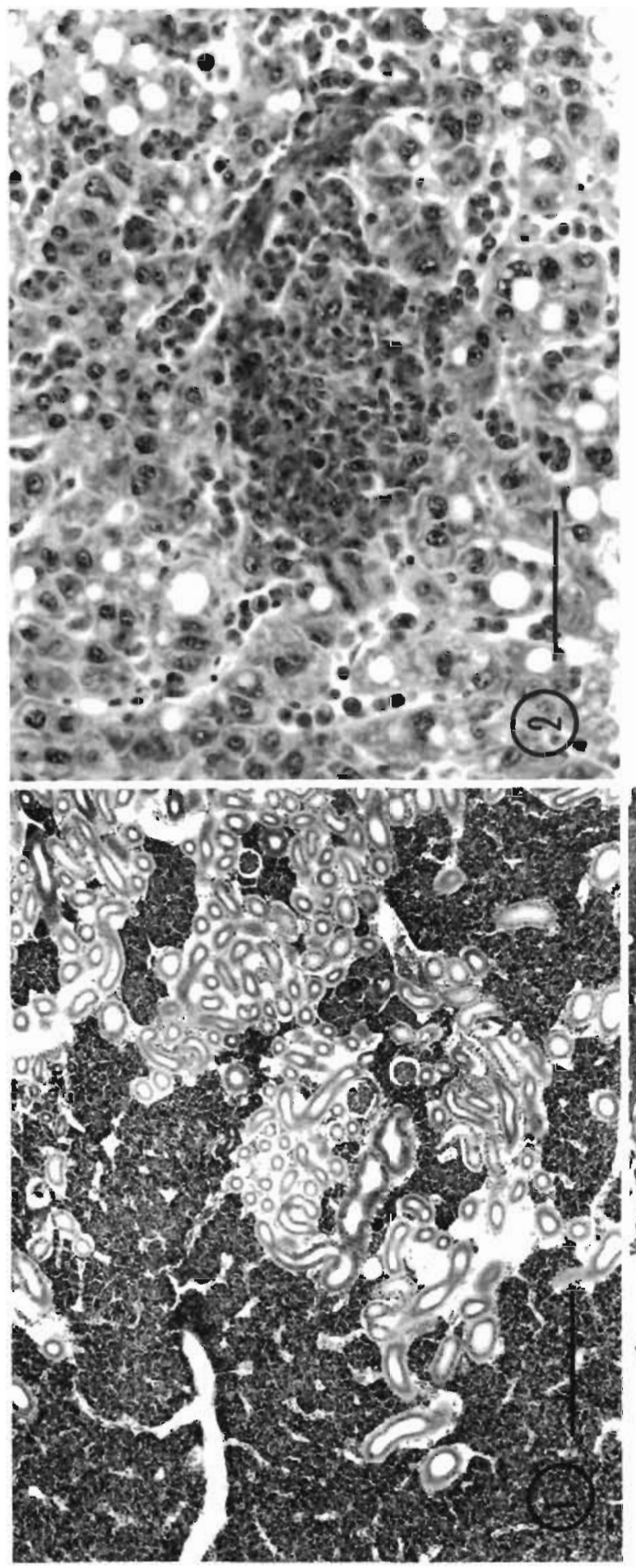

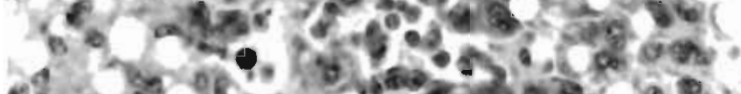

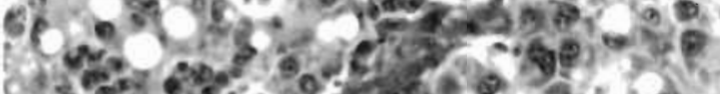

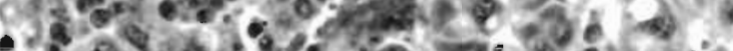
S.

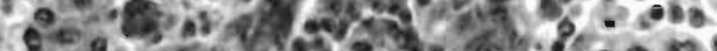

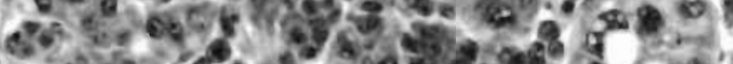

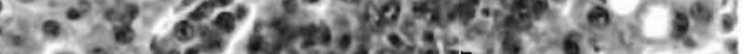

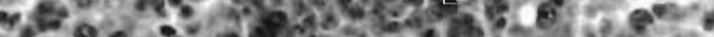
low 3 .

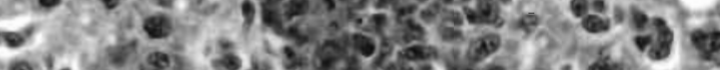

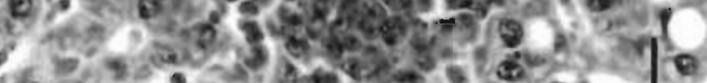

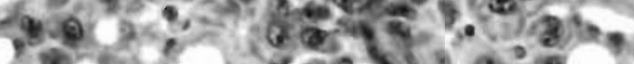

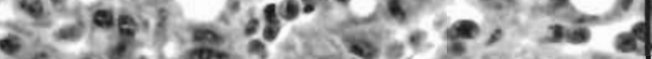

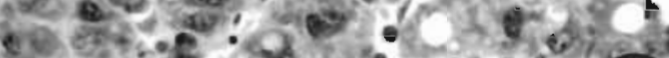

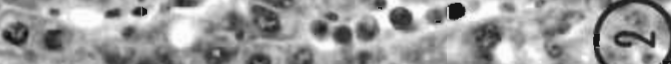

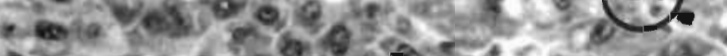

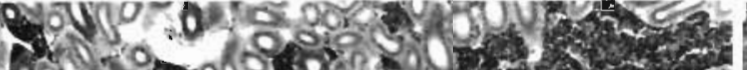

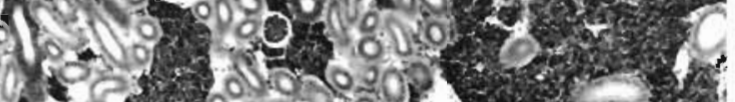

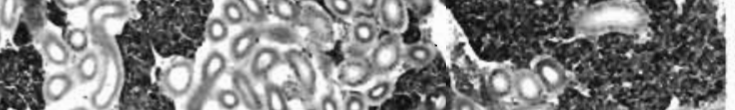
\%

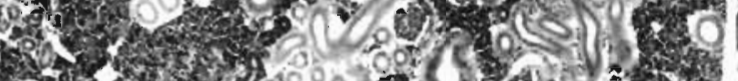

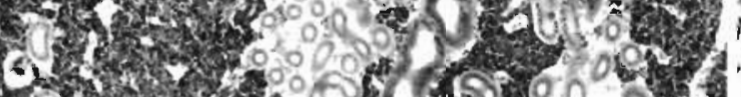

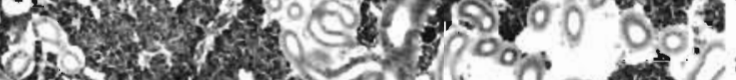

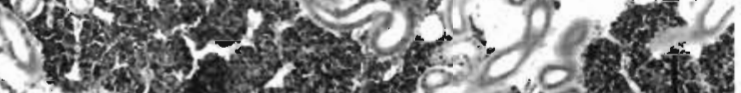
3.1.
品

$2 \div \xi$

홍요

돈

政

$\because 3 \infty$

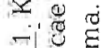

표

可

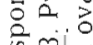

运

光宝绳

造

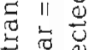

要递

完。

क

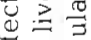

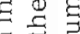

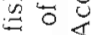

है $\dot{0}$

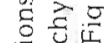

可的

西主

品

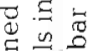

व

$\subseteq \tilde{Q}$

S

ธ

00

둘 무

흥

\%

(

I

$\Leftrightarrow$

है

ㄴ.

एक

궁

0

$\forall \Xi$

올

诖 


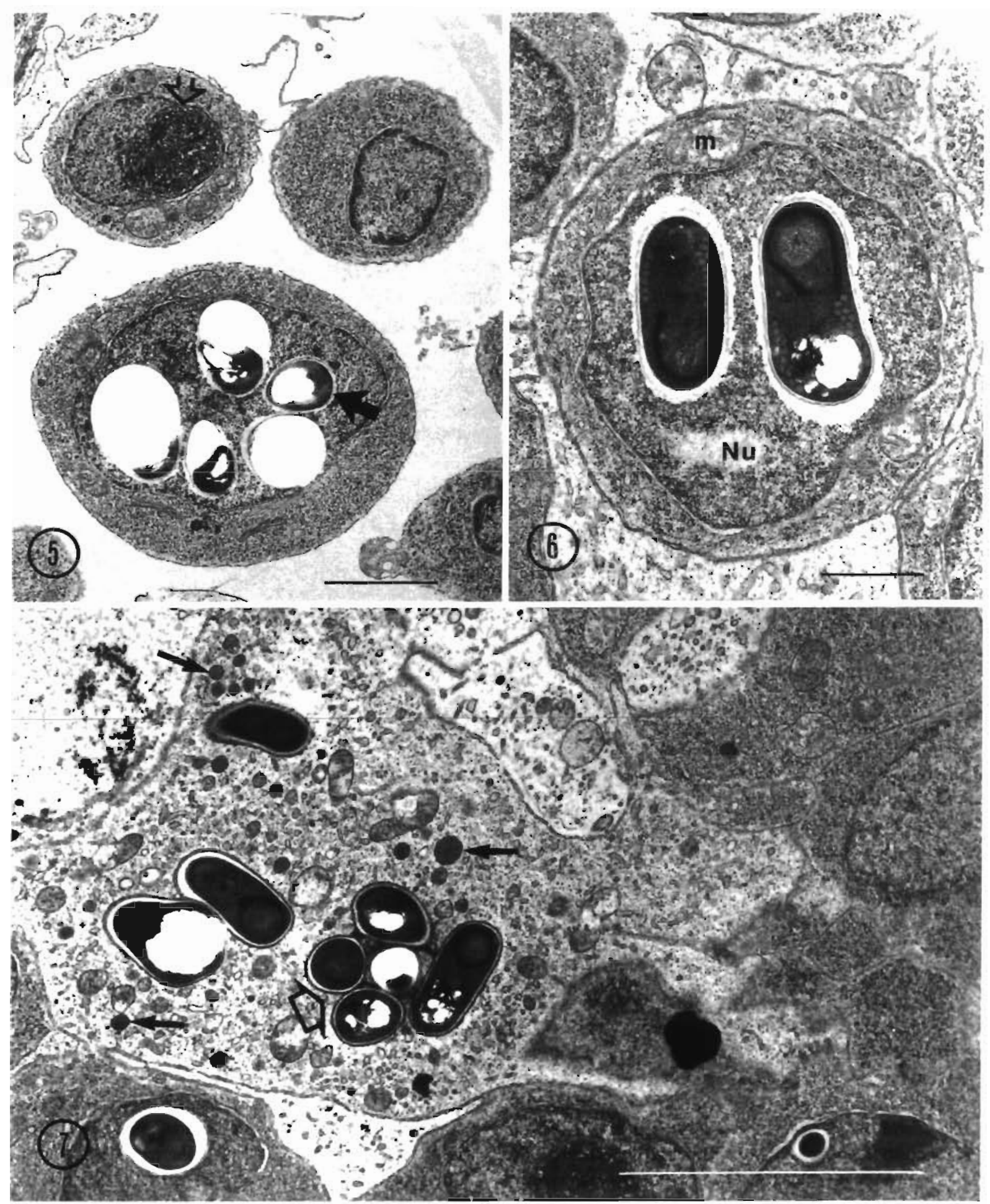

Figs. 5 to 7 Parasite infecting Cyclopterus lumpus. Fig. 5. Mature (solid arrow) and immmature (open arrow) stages of an intranuclear microsporidian parasite within the nucleus of circulating lymphocytes in a renal blood vessel. Note the poor infiltration of the mature spore with resin which is typical of microsporidia. Scale bar $=2 \mu \mathrm{m}$. Fig. 6 . Mature microsporidian spores within the nucleus of a lymphoblast-like cell in the kidney. m: mitochondrion; Nu: nucleus of lymphoblast-like cell. Scale bar $=1 \mu \mathrm{m}$. Fiq. 7. Microsporidian spores (open arrow) within the cytoplasm of a degenerate cell. Note the electron-lucent cytoplasm and numerous lysosomes (arrows). Scale bar $=5 \mu \mathrm{m}$ 


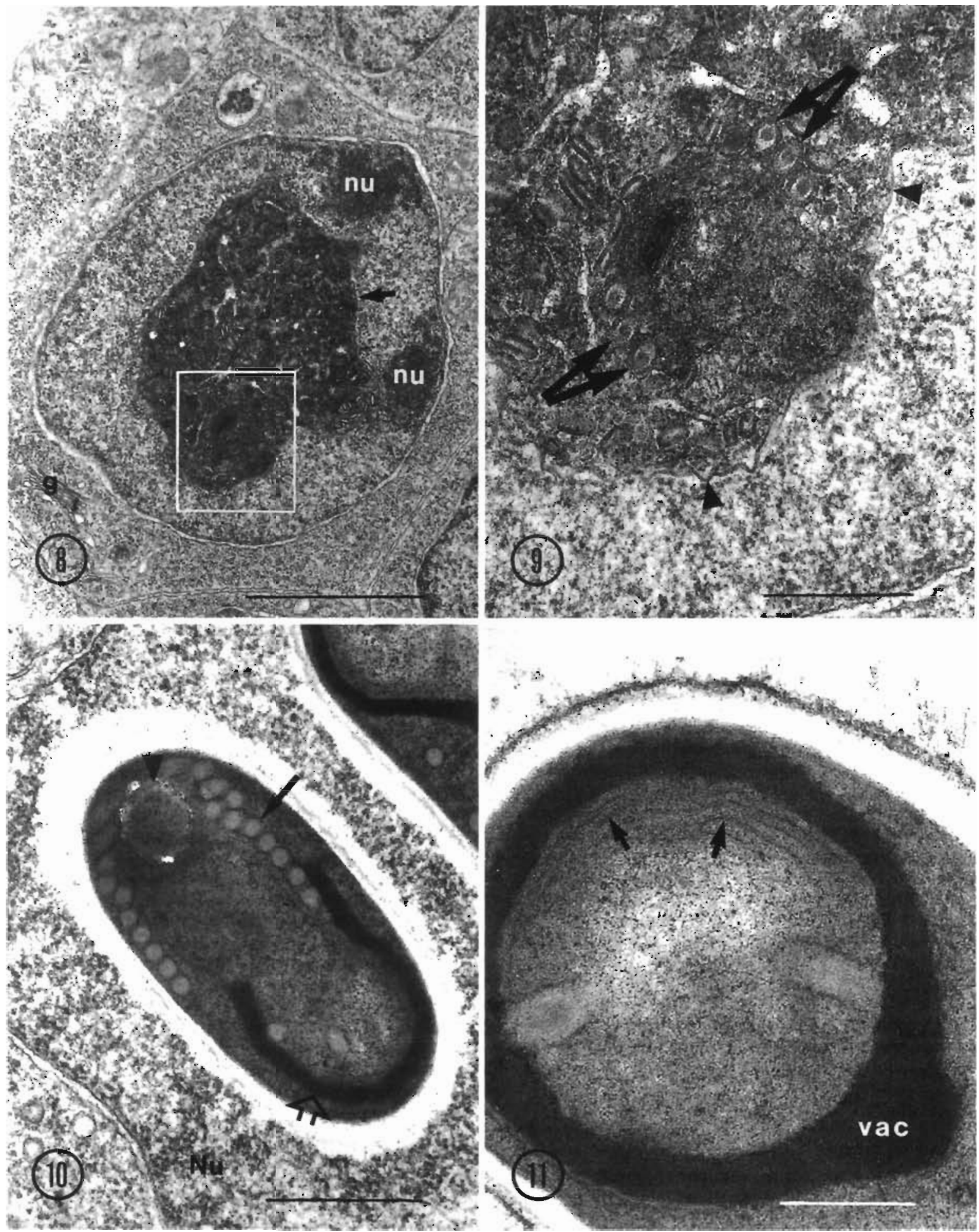

Figs 8 to 11. Parasite infecting Cyclopterus lumpus. Fig. 8. Membrane-bound (arrow) intranuclear inclusions within a polygonal lymphoblast-like precursor cell. nu: nucleolus; g: Golgi apparatus. Scale bar $=2 \mu \mathrm{m}$. Fig. 9. Enlargement of boxed section in Fig. 8 showing the regular arrangements of circular structures (arrows) within the membrane-bound nuclear inclusion (arrowheads). Scale bar $=0.5 \mu \mathrm{m}$. Fig. 10. Mature microsporidian spore with typical multicoiled polar tube (arrow), posterior vacuole (ruptured) (arrowhead) and polaroplast (open arrow). Nu: host cell nucleus. Scale bar $=1 \mu \mathrm{m}$. Fig. 11. Posterior vacuole of an isolated microsporidian spore. Note the numerous linearly arranged lamellar structures (arrows) within the vacuole (vac). Scale bar $=0.5 \mu \mathrm{m}$ 


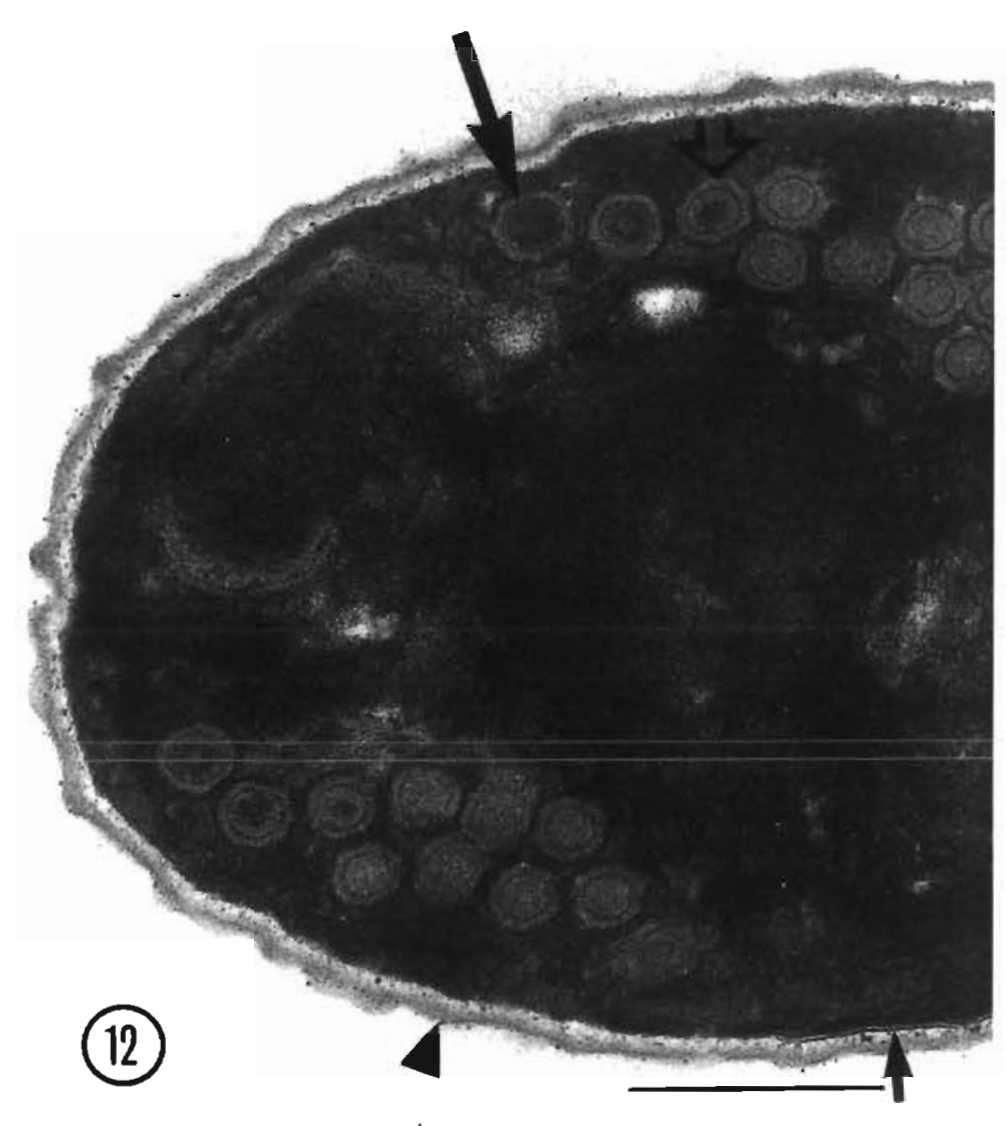

Fig. 12. Portion of an isolated microsporidian spore showing the polar tube composed of an electron-dense core (large solid arrow) and a less-dense outer sheath (open arrow). Note the external cell coat (arrowhead) distinct from the plasma membrane (small arrow). Scale bar $=0.25 \mu \mathrm{m}$

poietic stem cells (Elston et al. 1987 . Morrison et al. 1990) and less commonly in the rodlet cells, urinary tubule epithelial cells and mesangial cells of the glomerulus. $E$. bieneusi is observed in the enterocytes of human patients with acquired immunodeficiency syndrome (Desportes et al. 1985). Our case report suggests an affinity for cells with morphologic properties of lymphocytes and their precursors (large nucleus, compact chromatin, thin basophilic cytoplasmic rim).

The microsporidian observed herein is similar in description to both Enterocytozoon bieneusi (Desportes et al. 1985) and E. salmonis. Mature spores are similar in size and shape, and contain a central vacuole but a poorly differentiated endospore. E. salmonis and the lumpish Enterocytozoon sp. have a similar number of polar tube turns but $E$. bieneusi has fewer (4 or 5). All stages of $E$. salmonis and the lumpfish microsporidian are seen within the nucleus; however, $E$. bieneusi immature spores are found within the cytoplasm (Desportes et al. 1985, Cali \& Owen 1990). Both E. salmonis and the lumpfish Enterocytozoon sp. apparently migrate via the vasculature and produce a hyperplastic response in affected tissues.

A similar intranuclear agent, Microsporidium rhabdophilia, develops in the nucleus of rodlet cells of salmonid fishes although it does not cause disease (Modin

\section{DISCUSSION}

Lumpfish are a commercially important semipelagic species. They provide a source of roe for caviar production. Recently the culture of lumpfish has gained importance for alleviating unpredictability in the commercial supply of roe. With the development of any new species for aquaculture, disease problems emerge which may relate to husbandry methods.

The parasite within the lumpfish was identified as a microsporidian due to the presence of unicellular spores containing sporoplasm, a coiled polar tube, polaroplast and posterior vacuole. The intranuclear location of the parasite places it in the genus Enterocytozoon. There are only 2 previously described species from this genus, 1 in humans and 1 in salmonids.

Enteracytozoon salmonis (Chilmonczyk et al. 1991) infects Oncorhynchus tshawytscha primarily and $O$. mykiss in Washington and California. USA. The parasite is found predominantly in the nucleus of haemato-
1981). Its spore characteristics are consistent with Enterocytozoom salmonis, E. bienusi and the lumpfish Enterocytozoon sp. reported in our study.

Lumpfish mortalities were attributed to the microsporidian due to high numbers of spores seen in many body tissues of moribund fish and the hyperplastic tissue response which occurred with the presence of spores. Other infectious agents were not noted; specifically, viral particles were not detected during electron microscopic examination of infected tissues.

There is no licensed therapeutic treatment for microsporidia in fish. Fumagillin DCH was successfully used to treat microsporidiosis in eels (Kano \& Fukui 1982) and has been used against similar parasites, myxosporeans, in salmonids with equivocal results. Hedrick et al. (1988) successfully used fumagillin DCH in rainbow trout with experimentally induced proliferative kidney disease. Conversely Ibarra et al. (1990) found that this antibiotic failed to protect rainbow trout against experimentally or naturally induced ceratomyxosis. The potential efficacy of fumagillin DCH against this 
microsporidian in lumpfish is speculative, therefore health management strategies to prevent and control potential disease problems become important.

Microsporidian control in an aquaculture setup should be directed at breaking transmission of viable spores between the fish, hence interrupting infection. This may be accomplished by vigilant segregation of year classes through separate recirculation systems, thorough disinfection of nets and tanks, and, an all in/all out movement of fish.

Acknowledgements. The authors thank Dr L. Hammell and B. Maloney for their help in sample collection and processing.

\section{LITERATURE CITED}

Cali, A., Owen, R. L. (1990). Intracellular development of Enterocytozoon, a unique microsporidian found in the intestine of AIDS patients. J. Protozool. 37: 145-155

Chilmonczyk, S., Cox, W. T., Hedrick, R. P. (1991). Enterocytozoon salmonis $N$. Ap: an intranuclear microsporidian from salmonid fish. J. Protozool. 38 (3): 264-269

Desportes, I., Le Charpentier, Y., Galian, A., Bernard, F., Cochand-Priollet, B., Lavergne, A., Ravisse, P., Modigliani, R. (1985). Occurrence of a new microsporidan: Enterocytozoon bieneusi n. g., n. sp., in the enterocytes of human patients with AIDS. J. Protozool. 32: 250-254

Responsible Subject Editor: W. Körting, Hannover, Germany
Elston, R. A., Kent, M. L., Harrell, L. H. (1987). An intranuclear microsporidium associated with acute anemia in the chinook salmon. J. Protozool. 34: 274-277

Hedrick, R. P., Groff, J M., Foley, P., McDowell, T (1988). Oral administration of Fumagillin DCH protects chinook salmon Oncorhynchus tshawytscha from experimentally induced proliferative kidney disease. Dis. aquat. Org. 4: $165-168$

Hedrick, R. P., Groff, J. M., McDowell, T S., Willis, M., Cox, W. T. (1990). Hematopoietic intranuclear microsporidian infections with features of leukemia in chinook salmon Oncorhynchus tshawytscha. Dis. aquat. Org. 8: 189-197

Ibarra, A. M., Gall, G. A. E., Hedrick, R. P. (1990). Trials with Fumagillin DCH and malachite green to control ceratomyxosis in rainbow trout (Oncorhynchus mykiss). Fish Pathol. 25: 217-223

Kano, T., Fukui, H. (1982). Studies on Pleistophora infection in eel. Anguilla japonica - I. Experimental induction of microsporidiosis and fumagillin efficacy. Fish Pathol. 16(4): $193-200$

Luna, L. G. (1968). Routine staining procedures. In: Luna, L. G. (ed.) Manual of histological staining methods of the Armed Forces Institute of Pathology. McGraw-Hill, Toronto, p. 42-46.

Modin, J. (1981). Microsporidia rhabdophilia n. sp. from the rodlet cells of salmonid fishes. J. Fish. Dis. 4: 203-211

Morrison, J. K., MacConnell, E., Chapman, P. F., Westgard, R. L. (1990). A microsporidium-induced lymphoblastosis in chinook salmon Oncorhynchus tshawytscha in freshwater. Dis. aquat. Org. 8: 99-104

O'Grodnick, J. J. (1975). Whirling disease (Myxosoma cerebralis) spore concentration using the continuous plankton centrifuge. J Wild]. Dis. 11: 54-57

Manuscript first received: December 20,1993

Revised version accepted: June 21, 1994 